\title{
UMA LEITURA DO ARBITRISMO PORTUGUÊS A PARTIR DAS OBRAS O SOLDADO PRÁTICO E DA REFORMAÇÃO DA MILÍCIA E GOVERNO DO ESTADO DA ÍNDIA ORIENTAL
}

Priscila de Lima Orientação: Andréa Doré

PALAVRAS-CHAVE: União Ibérica, Reformas, Arbitrismo.

A construção do império ultramarino português foi desenvolvida ao longo dos séculos XV e XVI, consolidando a presença lusitana na África, Ásia e América. No entanto, pode-se afirmar que durante o século XVI foi o Oriente a peça mais cara aos lusitanos. A expedição de Vasco da Gama, enviada por D. Manuel em 1497, foi impulsionada pelo desejo de obtenção das ricas especiarias e pela busca de reinos cristãos que pudessem, de alguma forma, serem facilitadores da entrada de Portugal no cenário econômico e político da Ásia. ${ }^{1}$ A Índia foi o espaço que mais obteve atenção por parte da Coroa durante o século XVI e, ao mesmo tempo, o território mais almejado pelos portugueses que procuravam riquezas.

No entanto, após o período das conquistas desenvolveram-se vários entraves à continuidade da presença lusitana na Ásia. Reinos locais passaram, a partir de meados do século XVI, a disputar as principais redes comerciais movimentadas pelos portugueses. ${ }^{2} \mathrm{Na}$ primeira década do século XVII tiveram início as investidas de holandeses e ingleses que visavam minar a hegemonia lusitana. Ao lado das ameaças externas coexistiam as carências estruturais características do Estado da Índia, o que, de certa forma, contribuiu para a fragilidade das forças portuguesas perante essa conjuntura.

\footnotetext{
${ }^{1}$ THOMAZ, Luis Filipe F. R.. De Ceuta a Timor. Lisboa: Difel, 1994. p.193.

${ }^{2}$ Entre esses reinos pode-se citar o sultanato do Achém, situado ao norte da ilha de Samatra, os Otomanos e os Safávidas do Irão.
} 
Diante dessas circunstâncias, muitas foram as vozes que procuraram alertar sobre os maus caminhos que estavam em andamento e, ao mesmo tempo, buscaram apresentar possíveis soluções. Os objetivos desta pesquisa situaram-se nos debates sobre essa literatura crítica e reformista a partir das análises do Soldado Prático, de Diogo do Couto, e da Reformação da Milícia e Governo do Estado da Índia Oriental, de Francisco Rodrigues Silveira. Essas obras tiveram como intuito alertar sobre as crescentes dificuldades presentes no Estado da Índia e comprovar, através de seus exemplos, que se as causas dessa situação não fossem banidas as conquistas portuguesas seriam perdidas. Pois, nas palavras de Couto, "já na Índia não há cousa sã: tudo está podre e afistulado". ${ }^{3}$ Ao lado de suas previsões nefastas para a Ásia portuguesa, existiam outros aspectos comuns aos dois autores, visto que ambos eram de origem plebéia e serviram como soldados no Oriente português. Diogo do Couto partira para a Índia em 1559 e lá permaneceu até sua morte, em 1616. Francisco Rodrigues Silveira esteve nas fileiras da milícia oriental entre os anos de 1586-1598. ${ }^{4}$

Apesar das semelhanças entre os assuntos abordados pelos autores, os alvos principais de suas reformas eram diferentes. Para Couto o grande mal do Estado da Índia era a corrupção praticada pelos agentes régios. Já Silveira, apesar de discorrer sobre as práticas corruptas, era claro em seu posicionamento ao dizer "de nossa barbaríssima desordem nascem todas nossas desventuras, e tenhamos

${ }^{3}$ COUTO, Diogo do. O Soldado Prático. Lisboa: Livrarias Sá da Costa, 1954. p. 90. Couto organizou $O$ Soldado Prático sob a forma de diálogos fictícios entre um soldado experiente regresso da Índia para Portugal, um fidalgo ex-governador da Índia e um despachador. Já o livro de Silveira é um autêntico tratado, pois demonstra com clareza os males que afetavam a Índia e apresenta os remédios para a cura.

4 Diogo do Couto terminou seus dias como cronista oficial da história dos portugueses na Índia, continuando as Décadas da Ásia, iniciadas por João de Barros. As informações sobre a vida de Silveira são escassas, encontrando-se algumas referências ao longo de seu livro. 
para nós que a disciplina militar nos será na Índia para os males um frutífero remédio".

Tendo em vista o grande número de temáticas abordadas pelos autores, optei por desenvolver uma análise restrita àquelas que considero de maior peso e comum às duas obras, as quais são: a crítica ao modelo do império oriental, conjuntamente com os arbítrios sobre a territorialidade; a crítica à corrupção desenvolvida pelos oficiais portugueses; e as reformas militares.

Essa literatura reformista teve seu auge produtivo nas últimas décadas do século XVI e durante a primeira metade do século XVII e seus autores ficaram conhecidos como arbitristas. Foram os súditos da coroa espanhola os que mais utilizaram essa estratégia literária para poderem fazer-se ouvir nas Juntas e perante o monarca, pois na Espanha esses tratados contavam com uma certa institucionalização, visto que se o arbítrio fosse aceito seu autor recebia uma quantia como recompensa pelo serviço prestado à coroa. ${ }^{6}$

A historiografia referente a esse gênero literário que foi o arbitrismo é abundante para o caso espanhol, provavelmente devido a essa maior produção e à disponibilidade material das obras até os dias atuais. Para o caso português há uma visível defasagem de trabalhos historiográficos sobre $\mathrm{o}$ assunto. Normalmente as referências encontram-se em obras mais amplas, aparecem como tópicos no interior de outras temáticas. Assim, a presente pesquisa veio de encontro a essa carência de reflexões sobre a existência desse tipo de discurso para o império português no Oriente.

A análise dos discursos presentes nas citadas obras foi conduzida por questões centrais, como a importância da experiência para a elaboração desse tipo de literatura. Ao mesmo tempo, procurei

${ }^{5}$ SILVEIRA, Francisco Rodrigues,. Reformação da Milícia e Governo do Estado da Índia Oriental. Lisboa: Fundação Oriente, 1996. p.34.

${ }^{6}$ ALONSO, M. ${ }^{a}$ Luisa Martinez de Salinas. Contribucion Al Estudio Sobre Los Arbitristas. Nuevos Arbitrios para Las Indias a Principios Del Siglo XVII. Revista de Indias, 1990, Vol L, n ${ }^{\circ}$ 188. p.169; BRONNER, Fred. Tramitacion Legislativa Bajo Olivares. La Redaccion De Los Arbítrios De 1631. Revista de Indias, 1981, Vol XLI, nº 165-166. p. 413. 
pensar nas possíveis relações entre a União Ibérica (1580-1640) e a multiplicação desse tipo de literatura entre os súditos portugueses. Assim, buscou-se compreender o arbitrismo como decorrente de um momento histórico pontual, caracterizado tanto por uma crise política, representada pela própria união com Castela, como econômica e militar. Por outro lado, considerou-se que a opção pela literatura de arbítrios como meio de expressão de pessoas não envolvidas com os meandros políticos do reino esteve vinculada às trocas culturais entre portugueses e espanhóis.

A pesquisa foi desenvolvida a partir das contribuições de trabalhos historiográficos que discorrem sobre aspectos mais gerais do Renascimento, principalmente no que diz respeito à literatura política e aos escritos históricos, visto que as fontes em questão foram produzidas dentro de parâmetros de escrita correntes na época. Por outro lado, o entendimento dessa tradição arbitrista na Península Ibérica só foi possível através de leituras de trabalhos sobre o tema, principalmente aqueles que se remetem aos casos de arbitristas espanhóis. Procurei seguir as reflexões de pesquisa de Anne Dubet, que entende como essencial a análise da atuação desses indivíduos (os arbitristas) e, mais do que isso, suas concepções de sociedade e de poder. ${ }^{8}$

Optou-se por organizar a pesquisa a partir de três capítulos. $\mathrm{O}$ primeiro tratou dos escritos do renascimento europeu, apontando suas principais características para, num segundo momento, relacionar o Renascimento à expansão portuguesa, a partir das crônicas do século XVI sobre o Oriente. No segundo capítulo fez-se uma discussão sobre a União Ibérica, partindo de três pontos principais: a) o processo sucessório; b) a formação do império

${ }^{7}$ Silveira conta em seu livro que tentou por nove vezes encaminhar seu tratado para as Juntas em Madrid, fato que é elucidativo da adoção da prática espanhola de encaminhar os tratados para as instâncias competentes. Francisco Rodrigues Silveira. Op.cit. P.XXIV.

${ }^{8}$ DUBET, Anne. Hacienda, Arbitrismo y Negociación Política: los proyectos de erarios públicos y montes de piedad en los siglos XVI y XVII. Valladolid: Universidad de Valladolid. Secretariado de publicaciones, 2003. 
ibérico; c) as trocas culturais entre portugueses e espanhóis. O último capítulo foi dividido em três partes principais. A primeira fala da mudança de discurso sobre a Ásia portuguesa a partir de meados do século XVI; segue-se uma apreciação sobre a literatura de arbítrios na Península Ibérica; por fim, passa-se à análise das propostas de reforma para o Estado da Índia contidas nas obras $O$ Soldado Prático e a Reformação da Milícia e Governo do Estado da Índia Oriental.

Ao longo da análise das obras de Couto e Silveira foi possível perceber que a urgência por reformas e a experiência de ambos no Oriente foram os dois fatores legitimadores de seus discursos. O valor da experiência para a condução do Estado constituiu-se como um de seus principais arbítrios. A crítica contundente dos autores é expressa por Couto através da voz do soldado, segundo o qual "é esta maldição portuguesa tal, sua desconfiança tamanha, que homem que não é fidalgo não é chamado para nada". ${ }^{9}$ Também Silveira proclamava o favorecimento de homens de "linhagem obscura", mas práticos na guerra, para compor os cargos da milícia oriental. ${ }^{10}$ Fica evidente que os autores escreveram suas obras não apenas em prol de suas causas pessoais, pois se percebe que os arbítrios propunham o estabelecimento de uma sociedade mais eqüitativa no que diz respeito ao acesso aos Ofícios e Honras da monarquia.

Por outro lado, os arbítrios referentes às conquistas territoriais e às reformas militares não foram provenientes da genialidade dos autores, visto que, segundo o historiador Sanjay Subrahmanyam, as primeiras décadas do período Habsburgo foram caracterizadas pelas preocupações crescentes com os assuntos territoriais, cujos projetos visavam a África Oriental, o Ceilão e a Ásia do Sudoeste. ${ }^{11}$ Assim, é possível dizer que as duas obras aqui analisadas refletem tendências comuns da época em que foram elaboradas, demonstrando que seus

\footnotetext{
${ }^{9}$ COUTO, Diogo do. Op.cit. p.92.

${ }^{10}$ SILVEIRA, Francisco Rodrigues. Op.Cit. p.139.

${ }^{11}$ SUBRAHMANYAM, Sanjay. O Império Asiático Português, 1500-1700: uma história política e econômica. Lisboa: Difel, 1993, p.172.
} 
autores partilhavam as mesmas expectativas de muitos de seus contemporâneos.

Ademais, pode-se afirmar que a conjuntura de crise presente no Estado da Índia não pode ser tomada como a principal causa da proliferação desses escritos, pois na história portuguesa já tinham ocorrido períodos de crise sem gerar, no entanto, semelhante literatura. Dessa forma, na presente pesquisa, o fenômeno do arbitrismo foi pensado como uma expressão do intercâmbio cultural entre espanhóis e portugueses durante o período filipino e também teve conexões com tradições políticas, que asseguravam aos súditos capazes o direito de se dirigirem ao monarca. 